\title{
Joy of Learning Through Internet Memes
}

\author{
https://doi.org/10.3991/ijep.v10i5.15211 \\ Rishabh Reddy, Rishabh Singh, Vidhi Kapoor \\ NMIMS University, Mumbai, India \\ Prathamesh Churi $\left({ }^{凶}\right)$ \\ NMIMS University, Mumbai, India \\ Symbiosis International, Pune, India \\ Prathamesh.churiegmail.com
}

\begin{abstract}
The currency of today's social media is influence. The influence is any action or reaction by which you can drive your thoughts on people's mind through social platforms. Internet memes are getting very popular in today's generation. With the rise of technology and technological devices, the ability of concentration of young minds has drastically reduced. In a typical case, the classroom-based teaching tools like blackboard, PPT, videos are no more appreciated by the newer generation. This is because today's generation is practical oriented and wants skills to acquire and do not want traditional teaching which enforce memory rather than knowledge. They want classroom-based teaching methods to be innovative. Looking at the popularity of the memes, the paper shares and experiences of use of internet memes from existing papers available on the internet. Based on the available literature survey, the two research questions were formed in order to examine the perception on memes in student's mind. The survey of 201 student population is statistically analysed and hypothesis testing was also conducted. It is overserved that students are more positively agree to use of memes in classroom teaching. Another viewpoint in this paper is the use of memes are incorporated in test papers. The acceptance of inclusion of memes in mid-term test papers proves that learning through memes is now new normal in today's generation.
\end{abstract}

Keywords - Internet memes, learning, youth, perception.

\section{Introduction}

The usage of the internet is increasing day by day. According to the statistics given in [1], Till the year 2017, there were a total 3.9 billion Internet users worldwide, which has increased to 4.5 billion in 2020 . If you see this number, it is more than half of the world's population. No doubt that the use of the internet will drastically increase in near future. The figure 1 [2], shows the statistics about the usage of the Internet worldwide. 


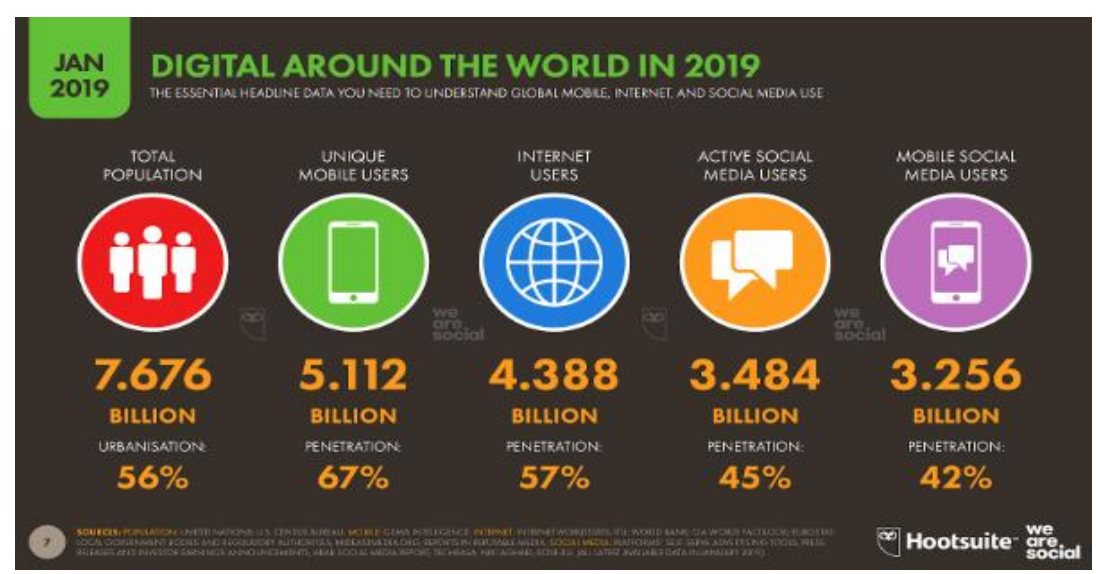

Fig. 1. Usage of internet worldwide [2]

Today's generation is a fan of technology and social media. In earlier days, social media was used to explore information and was considered as one of the good forms of communication. Nowadays, apart from the basic purpose, it is also being used as one of the forms of entertainment [3][4]. Communication has tremendously increased in one special form in today's generation, we often call them "Internet memes". It consists of a combination of funny images and texts that allude to specific situations, cultural references, or interest groups, through quick commentary, mood expression or plain mockery, memes point to the existence of a series of communication codes of great reach that are, however, used locally and in different languages. According to [5], The genealogy, evolution, and popularity of memes are one of the most intriguing developments of the internet as a communication space in recent years. The internet meme was first introduced by Richard Dawkins in his studies related to genetics and memetic as a cultural unit. According to him the meme spread like a gene [6]. Within a less period it has become popular among the younger generation and today memes are even used widely in a variety of fields like advertising and marketing, politics etc. [9][18] [19][20][21].

The extensive use and popularity of memes is going in the educational field also[7]. In the classrooms, instructors can use memes to explain the complex concepts in a simpler way. Memes are massively incorporated in learner's life [8]. Teacher can also make interesting memes which can be a part of his PPT during the class. Internet memes never solves the problem of complex concepts, but it simplifies the complex procedure of any topic taught by the teacher. There are various experiments conducted in the classrooms to study the effect of memes on the psychology of students. Various surveys and interviews from the existing research documents conclude that the memes are proven as a best supportive tool for teaching learning.

The contribution of the paper is a summary of all such research experiments conducted inside the classrooms. Authors searched some good quality papers on education through memes on google scholar platform. The availability of research documents on education through memes is very less. Authors of this paper picked up some good 
papers on the internet and wrote a summary of the work done and addressed the outcomings of this idea of introducing meme-based education.

The authors of this paper conducted an experimental based survey on the perception of memes in students regarding the introduction of memes as a mode of teaching. The survey is conducted among the engineering students of NMIMS university. This is done to interpret the correct way to introduce memes in the teaching learning process through statistical measures. Using the responses acquired from the surveys, hypothesis testing has been done, followed by statistical analysis that suggests that use of internet memes could be useful in engineering study. Addition to this, the student's results of mid-term tests are compared with previous academic years when internet memes were used in their test papers. The paper does not prove the fact that - Internet memes are important to be used by teacher, rather it shares an experience of including memes in traditional classroom-based teaching-learning.

\section{Existing Work on Meme-Based Learning}

The use of internet memes in teaching is not new. Authors have searched some quality papers on google scholar and Scopus platform. Total 13 papers were found, and 5 papers were found irrelevant to our research study. The summary of 8 papers are described in this section.

The paper [10] talks about triggering the human emotion of laughter in Russian culture with the help of modern digital technology. Internet memes are the primary mode to spread laughter through digital media. Memes in Russia were termed by the researchers as 'media virus' and 'internet phenomenon'. As per the research conducted using various social media applications, the media that attracted most users was explicitly connected to laughter and a huge percentage of which was memes. Pictorial memes have a larger impact than textual memes, solely because anything that can be visualized is understood better. However, as per research the quality of memes in the Russian laughter society was not that rich. The memes were categorized into several different categories and subcategories, and a detailed study was done about each one of them. The choice of memes by users depends upon various factors like age, gender, professional preference and culture. Users can show appreciation or disregard towards a meme through emoji, comments or likes.

According to the paper [11], memes can be of any form, that is, tunes, ideas, phrases or even clothing fashion. As memes involved into internet memes there were a few rules or syntaxes established. Nowadays, memes are generally developed using various templates, these templates have a common text, audio, video or picture and by keep that constant and changing the other factors new memes are formed. Mathematics can be taught and illustrated effectively using internet memes, as an example a meme that could correct the common mistake that students make by missing the negative values while taking the square root has been shown. The meaning of every meme has been categorized into three types, namely structural, social and specialized levels. The mathematical knowledge is included in the specialized level, but the teaching is considered effective only if the full meaning of the meme is understood by the recipient. 
Augmented Reality coupled with a GPS enabled device can be used to develop a higherlevel meme-video combination for explanation. There have already been efforts to include internet memes in the teaching systems of the world.

The paper [12] has introduced the photo sharing social media platform Instagram as medium of teaching. This experiment led to students being more interactive and interested in learning than any other medium applied thus far. Instagram is one of the most widely used social media platform and teaching through it is more versatile, humorous and engaging than the traditional written or PowerPoint presentation bases teaching. It is also effective way of knowing if the student has understood a topic because if they can interpret the given content while navigation then they have understood the concept of the meme. Students can show approval or disapproval and suggestions through likes and comments. Students who have missed the scheduled class or want revision to have the entire archive for reference available at any point of time. This method is difficult to implement due to the socially reactive nature of students and tough methods required for evaluation.

The use of technology for the teaching learning process is increasing rapidly and the traditional paper-based circulars are being replaced by WhatsApp group messages. This paper [13] says that the vehicle of information being passed on should be chosen as per its effectiveness, and memes have turned out to be very effective. Instagram can be used as it uses more images and less text for representation of data. The complexity of the meme can be altered and is decided as per the recipient audience response towards the memes. The meme has two major factors, the amount of humor and the amount of information in it. If a meme has all the required information but is not funny then it does not get a positive response, on the other hand if the meme is only humorous but does not contain the entire information it does not solve the purpose. Hence, each meme should be balanced and have adequate information while being humorous at the same time for better effectiveness.

The paper [14] talks about how internet memes which are referred to racism do or do not offend the people facing it and the ideology behind creating such memes which is referred to as color-blindness. There are two modes by which we depict the memes which might or might not offend different races. One of them is called the critical mode analysis and the other it's called the multimodal disclosure analysis. We also see that how we take this usage of memes related to racism to a teaching structure and educate people as this is also so called an art activity for the students and teachers need to teach them about hoe to maintain the intellectual and emotional balance so that it won't hurt anybody's feelings. Talking about CMA or CDA it is an analysis which carries out to find out the actual meaning behind the text which is used in a meme which depicts the emotion which is being conveyed to the audience and MDA deals with the actual pictorial representation by which people want to spread a message amongst the audience . These two methodologies and analogies carry a great importance about a meme. Images have addressed the meaning of racism, how they address racial issues, and what ideological assumptions are hidden in the coupling of visual images and texts. The denial of racism manifests as a rhetoric insisting that racism is a matter of perspective or racial injustice that comes from faults of people of color rather than the social system. racism manifested in various ways in Internet memes, including stereotyping, othering, and the 
denial of structural racism. Teachers should thoughtfully respond to students' questions and set the tone that welcomes open inquiry in racial issues.

The paper [15], we will be able to understand how the internet memes have been used for understanding interpersonal communication. Memes are units of cultural information that spread from one person to the next by means of replication and imitation. We need to understand that today's generation will not be able to understand the theoretical concepts as the technology has become a part of life and which affects all the powers of grasping information through a plane text. In this experiment conducted by the professor helps us understand that students today have been using social media platforms to spread knowledge amongst their class. Students curate and analyze Internet memes to demonstrate their understanding of interpersonal communication concepts. One of the major benefits of having undergraduate students explain interpersonal concepts through memes is that it harnesses their innate digital nativity. This will also allow students to not only be creative but also makes them focus on what the professor is teaching in the class. Assessment of other people of the class will help them to understand and grasp the topic really well as there is a atmosphere of competition around. Humor improves students' understanding and promotes retention and recall of course material.

Active learning [16] is one technique which will help build the brain capability to grasp, to think, to analyze, to debate and the simulations that every student carries out in daily learning activities. Critical thinking is very important when it comes to learning and help students to build this skill as students perform poorly on critical thinking evaluations that rely on memorization. To develop the critical thinking ability in students, the instructor asked the students to create political memes which will be based on their own evidence based political arguments and this will allow students to be critical about the content off the memes that they are exposed to day to day life. It has become increasingly important for people to view content on the Internet with some skepticism. Critical thinking encourages students to engage in various levels of critical thinking and encourages students to be skeptical of what they view on social media websites and to be mindful of the accuracy of the content they share.

Learning as well as Teaching methodologies have been studied and explained in various papers and now, we need to learn the didactical usage of mathematical memes which will make the concepts of the subject easy to learn and understand [17]. Students are asked to make memes which should be based on the concepts of mathematics which is taught by their professors and by the methodologies of CDA and MDA these memes have been reviewed by the instructor and he found out that students are understanding the concepts in a way of humor. Based on special and social meaning these memes were generated and these are the two types of emotions which is followed by the students to create a meme. Knowledge is built moving along the specialized meaning social to the specialized meaning and emotions are deeply tangled with the whole path. Anyway, uncharted territory is worth exploring, because, even if digital culture can be labelled by someone as a non-culture, facing the evidence that our students are emotionally embedded in it, it would be educationally valuable to embrace it and turn it into a cognitive opportunity. 
From [13] and [17] we found out how survey is a critical mode of analyzing any data generated by the audience and we know how this data can be used for various purposes such as prediction and learning. The survey helps us to find out the true emotion of what our audience feels about a topic. The authors of the paper have taken a reference from the paper and have conducted a similar survey (Based on RQ1 in Section 4) on how the memes have an impact on youth in a way of learning process. Additionally, we also compared the tests results of current year with the previous year for a course where the memes are used (Based on RQ2 in Section).

The detailed methodology plan is drawn in fig 2 below.

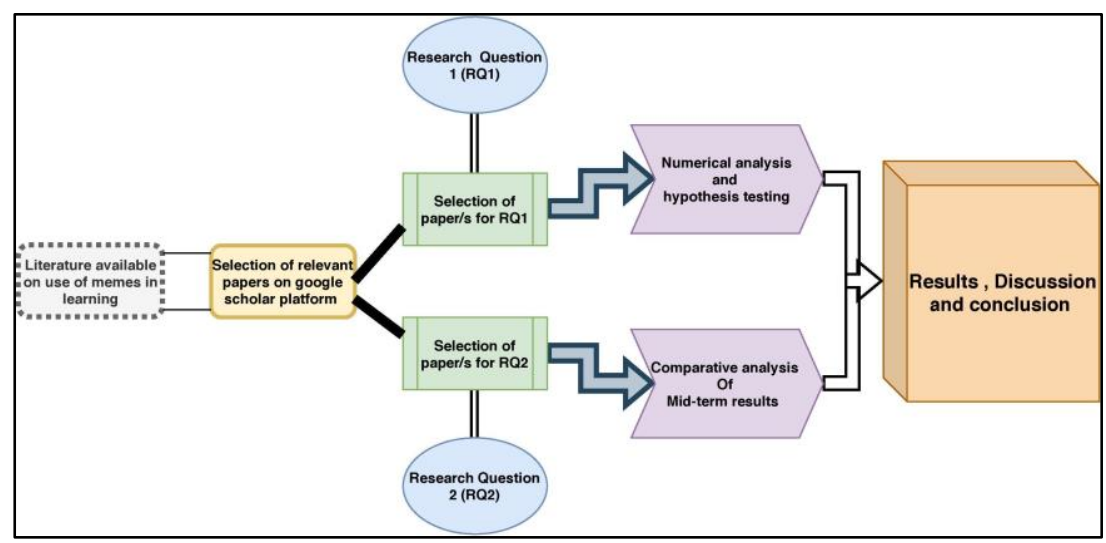

Fig. 2. Methodology plan for proposed research work on perception on memes

\section{Research Questions}

In order to augment the fact that learning through internet meme is a fun and joyful, we prepared 2 research questions and we answered them through various analysis conducted through public surveys. 
The details of research questions are tabulated below:

Table 1. Research Questions

$\begin{aligned} & \text { Research } \\
& \text { Questions }\end{aligned}$
\begin{tabular}{|l|l|l|} 
RQ1 & $\begin{array}{l}\text { What is the perception of students regarding } \\
\text { the inclusion of memes in classroom practices? }\end{array}$ & $\begin{array}{l}\text { A statistical analysis of around 200 popula- } \\
\text { tion is presented in the section 4.1. and 5.1. }\end{array}$ \\
\hline $\mathbf{R Q 2}$ & $\begin{array}{l}\text { What is the impact of including meme in class- } \\
\text { room practices? }\end{array}$ & $\begin{array}{l}\text { The results of midterm tests of current and } \\
\text { previous semester are presented in section } \\
\text { 4.2. and 5.2. }\end{array}$ \\
\hline
\end{tabular}

\section{Methodology and Socio Demographic Information of Population Sample}

\subsection{Methodology for RQ1}

In response to RQ1, a survey was conducted for 200 students of the engineering college of NMIMS University. The engineering college consists of students enrolled in Bachelor of technology (B-Tech) course (59\%) and MBA in technology management (MBA-Tech) course (41\%). The average age of the students is 20 years. Out of 200 students, $62 \%$ were male and the rest $38 \%$ were female. The survey was conducted to prove our study on memes and the students were asked a few questions on which the hypothesis testing and some statistical measures like mean and median were conducted. Suitable null and alternative hypothesis were taken into consideration to prove whether the students are on the agreement side of the statement or on the disagreement side. Box plot graph was also drawn for a better understanding of the distribution of our data. The rating are kept from 1 - Strongly agree to 5- Strongly disagree. The survey questions are taken from the research study done in [13]. The details of the results are included in section 5.1.

\subsection{Methodology for RQ2}

In order to answer the RQ2 stated in section 5, the midterm performance of the students who enrolled in the current year are compared with last year's student performance. The memes were included in the normal assessment of the student for the course of Multimedia Systems and Virtual Reality (abbreviated as MSVR). The students are in their undergraduate course of Computer Engineering from NMIMS University, School of Technology Management and Engineering. In the current academic year, students had undergone 3 midterm tests as their regular internal assessment. This year while setting papers for midterm, instructors included memes in MSVR course. Additionally, the few questions were also comprised of memes case studies. Meme doesn't directly impact on student's performance, but it helps students to create interest while solving the question papers. The results of this academic year is then compared with the previous year students' performance which uses the traditional approach of solving 
midterm question paper (no memes neither meme-based case study were included, all the questions were purely theoretical). The results show that meme-based approach improvise the results significantly on the students' performance this year. The details of the results are included in section 5.2.

\section{$5 \quad$ Results and Discussions}

\subsection{Statistical analysis of survey (RQ1)}

RQ 1: What is the perception of students regarding the inclusion of memes in classroom practices?

The table 2 shows the percentage calculation of survey on percentage on memes. From the table, people are more towards use of memes in classrooms. Most of them thinks that use of memes is helping them to understand the concepts better. The graphical representation of above survey is drawn in bar graph in figure 3.

Table 2. Survey Response of perception on memes.

\begin{tabular}{|l|c|c|c|c|c|}
\hline \multicolumn{2}{|c}{ Survey Questions Strongly Agree } & Agree & Neutral & Disagree & $\begin{array}{c}\text { Strongly } \\
\text { Disagree }\end{array}$ \\
\hline Engagement by memes & $47 \%$ & $38.50 \%$ & $12.50 \%$ & $1.50 \%$ & $0.50 \%$ \\
\hline $\begin{array}{l}\text { Teaching learning in- } \\
\text { teresting by memes }\end{array}$ & $38 \%$ & $44 \%$ & $13 \%$ & $3 \%$ & $2 \%$ \\
\hline $\begin{array}{l}\text { Understanding of } \\
\text { course better by memes }\end{array}$ & $24.50 \%$ & $39 \%$ & $28 \%$ & $6 \%$ & $2.50 \%$ \\
\hline $\begin{array}{l}\text { Topic diversion by ex- } \\
\text { tensive use of memes }\end{array}$ & $27.50 \%$ & $44 \%$ & $23 \%$ & $4 \%$ & $1.50 \%$ \\
\hline $\begin{array}{l}\text { Combination of teach- } \\
\text { ing with social media }\end{array}$ & $21 \%$ & $36 \%$ & $28 \%$ & $12.50 \%$ & $2.50 \%$ \\
\hline
\end{tabular}

This figure is edited one but colours changing, next below is original one, keep one 


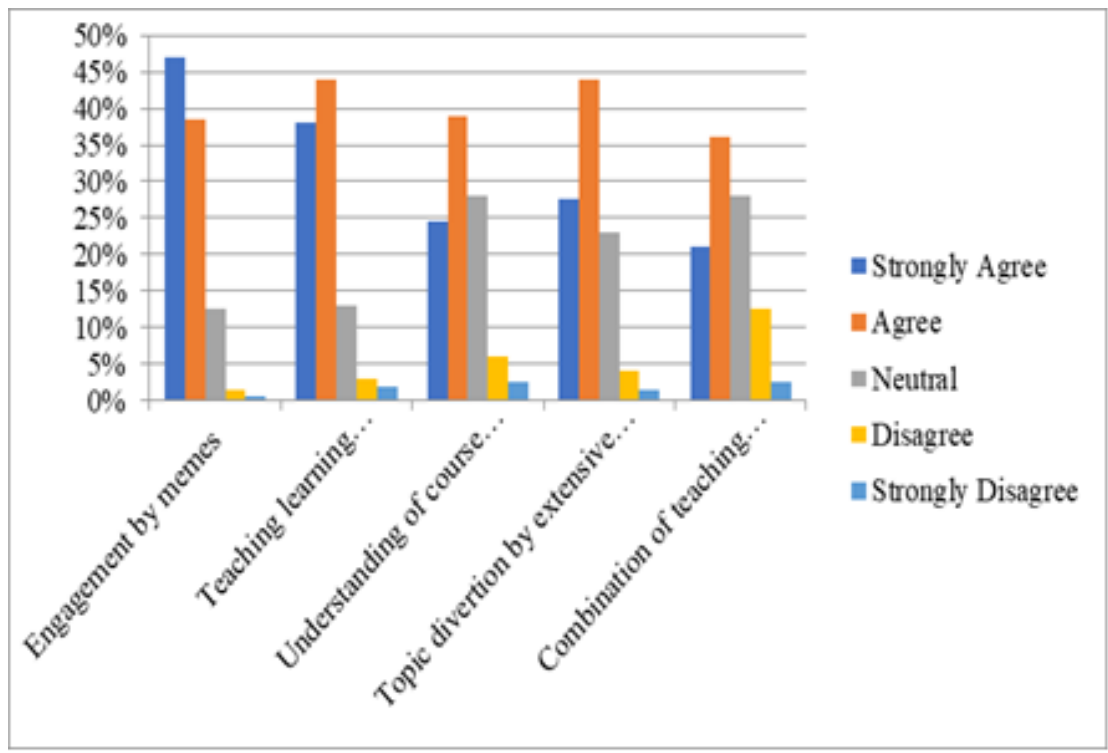

Fig. 3. Bar graph of Survey Response of Public perception on memes

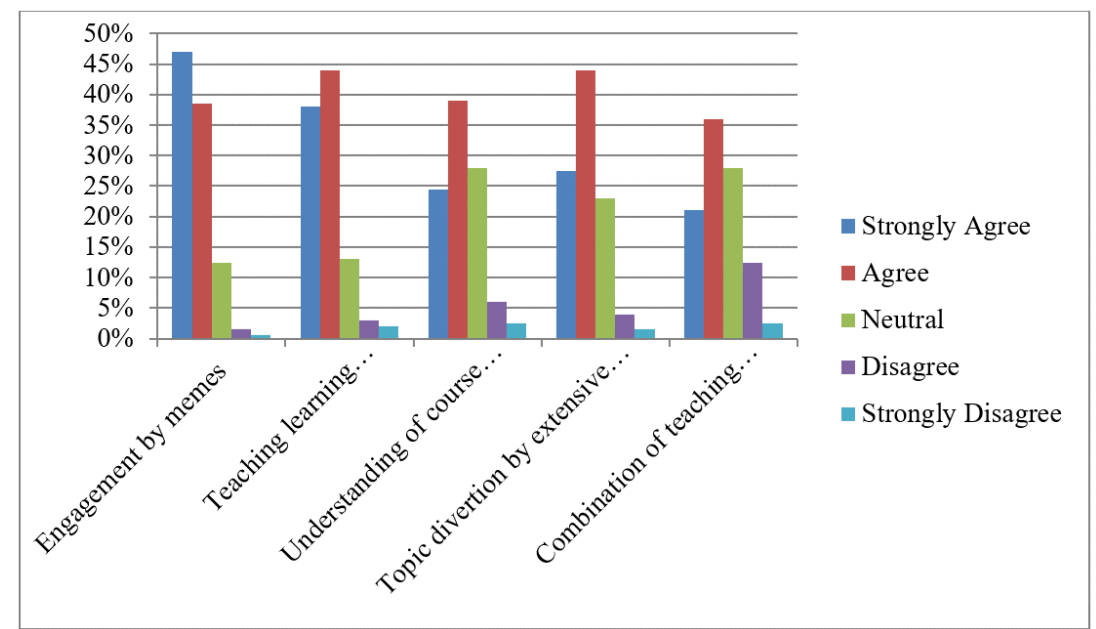

Fig. 4. Bar graph of Survey Response of Public perception on memes 
Table 3. Statistics of hypothesis testing conducted on 201 samples (RQ1)

\begin{tabular}{|c|c|c|c|c|c|c|c|c|}
\hline $\begin{array}{c}\text { Survey } \\
\text { Questions }\end{array}$ & Mean & Median & $\begin{array}{l}\text { Standard } \\
\text { deviation }\end{array}$ & Skewness & $\begin{array}{l}\text { Acceptance } \\
\text { region }\end{array}$ & $\begin{array}{c}\text { Calculated } \\
\text { value }\end{array}$ & $\begin{array}{l}\text { Result of } \\
\text { hypothe- } \\
\text { sis }\end{array}$ & $\begin{array}{l}\text { Conclu- } \\
\text { sion }\end{array}$ \\
\hline $\begin{array}{l}\text { Memes } \\
\text { keep you } \\
\text { engaged for } \\
\text { a longer pe- } \\
\text { riod }\end{array}$ & 1.7 & 2 & 0.783 & $\begin{array}{l}\text { Positively } \\
\text { skewed }\end{array}$ & $\begin{array}{l}\text { Between - } \\
1.645 \text { and } 0\end{array}$ & -23.48037 & \begin{tabular}{|l} 
Null hy- \\
pothesis \\
is rejected
\end{tabular} & $\begin{array}{l}\text { Memes do } \\
\text { keep the } \\
\text { students } \\
\text { engaged } \\
\text { for a } \\
\text { longer pe- } \\
\text { riod of } \\
\text { time. }\end{array}$ \\
\hline $\begin{array}{l}\text { Use of in- } \\
\text { ternet } \\
\text { memes } \\
\text { makes } \\
\text { classroom } \\
\text { teaching } \\
\text { learning in- } \\
\text { teresting }\end{array}$ & 1.87 & 2 & 0.893 & $\begin{array}{l}\text { Positively } \\
\text { skewed }\end{array}$ & $\begin{array}{l}\text { Between - } \\
1.645 \text { and } 0\end{array}$ & -17.89950 & \begin{tabular}{|l|} 
Null hy- \\
pothesis \\
is rejected
\end{tabular} & \begin{tabular}{|l} 
Classroom \\
teaching \\
learning \\
becomes \\
interesting \\
by the use \\
of internet \\
memes.
\end{tabular} \\
\hline \begin{tabular}{|l|} 
Internet \\
memes help \\
you under- \\
stand your \\
course bet- \\
ter
\end{tabular} & 2.23 & 2 & 0.971 & $\begin{array}{l}\text { Positively } \\
\text { skewed }\end{array}$ & $\begin{array}{l}\text { Between - } \\
1.645 \text { and } 0\end{array}$ & -11.22081 & \begin{tabular}{|l|} 
Null hy- \\
pothesis \\
is rejected
\end{tabular} & $\begin{array}{l}\text { Internet } \\
\text { memes } \\
\text { helps the } \\
\text { students to } \\
\text { understand } \\
\text { their } \\
\text { course bet- } \\
\text { ter. }\end{array}$ \\
\hline $\begin{array}{l}\text { Extensive } \\
\text { use of } \\
\text { memes may } \\
\text { divert the } \\
\text { exact topic } \\
\text { which } \\
\text { teacher is } \\
\text { teaching }\end{array}$ & 2.08 & 2 & 0.893 & $\begin{array}{l}\text { Positively } \\
\text { skewed }\end{array}$ & $\begin{array}{l}\text { Between - } \\
1.645 \text { and } 0\end{array}$ & -14.56846 & $\begin{array}{l}\text { Null hy- } \\
\text { pothesis } \\
\text { is rejected }\end{array}$ & $\begin{array}{l}\text { Extensive } \\
\text { use of } \\
\text { memes can } \\
\text { divert the } \\
\text { teacher and } \\
\text { the stu- } \\
\text { dents from } \\
\text { the exact } \\
\text { topic. }\end{array}$ \\
\hline $\begin{array}{l}\text { Teaching of } \\
\text { any course } \\
\text { with social } \\
\text { media }(\text { eg. } \\
\text { Instagram) } \\
\text { is the best } \\
\text { combina- } \\
\text { tion }\end{array}$ & 2.39 & 2 & 1.032 & $\begin{array}{l}\text { Positively } \\
\text { skewed }\end{array}$ & $\begin{array}{l}\text { Between - } \\
1.645 \text { and } 0\end{array}$ & -8.293523 & $\begin{array}{l}\text { Null hy- } \\
\text { pothesis } \\
\text { is rejected }\end{array}$ & $\begin{array}{l}\text { The combi- } \\
\text { nation of } \\
\text { teaching } \\
\text { with any } \\
\text { social me- } \\
\text { dia is the } \\
\text { best way or } \\
\text { the ideal } \\
\text { way of } \\
\text { teaching. }\end{array}$ \\
\hline
\end{tabular}




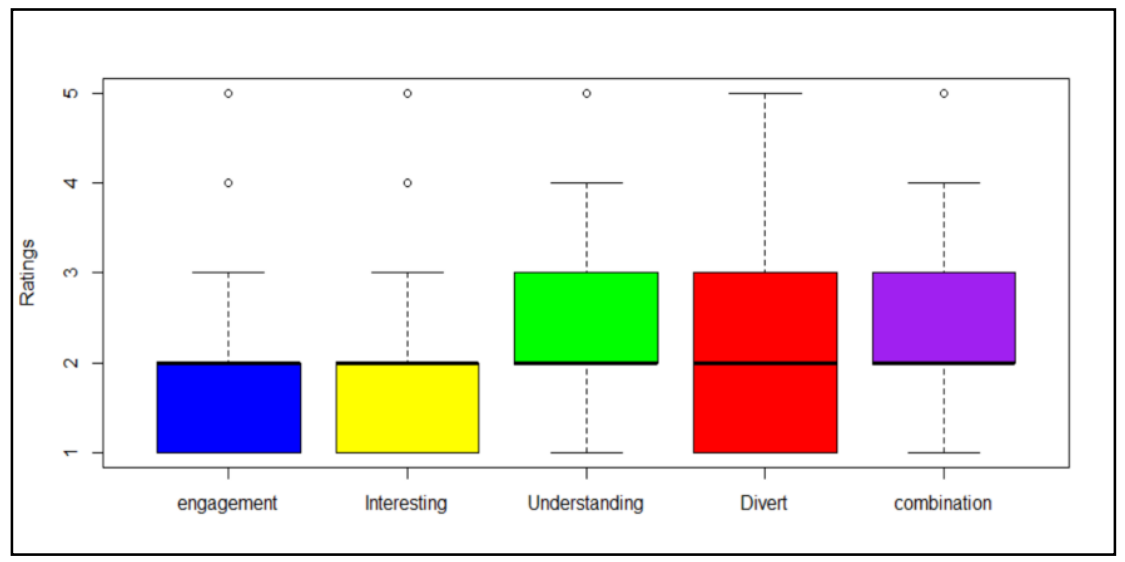

Fig. 5. Box plot Statistical Analysis of Hypothesis Testing

The ratings are between 1-5. 1 being on the strong agreement side and 5 being on strong disagreement side. In all hypothesis testing of different statements, we have taken the null hypothesis as greater than or equal to three (disagreement side) and alternative hypothesis less than 3 (agreement side). 5\% is kept as the significance level. 3 (Neutral) is chosen to be as a standard value because we want to prove whether the students are on the agreement side or the disagreement side for the following statements.

H1: Memes keep you engaged for a longer period of time:

Null hypothesis: The rating of engagement by memes is greater than or equal to three's

Alternative hypothesis: The rating of engagement by memes is less than 3 .

As seen in Table 2, null hypothesis is rejected. Hence by doing the hypothesis testing, it is proved that the students agree that memes keep them engaged for a longer period.

In the box plot drawn (Figure 4), we see that more than $75 \%$ of the data points are in between 1 and 2 (lower quartile is 1 and median is 2). There is no upper quartile because most of the data points are either 1 or 2 only. The maximum value in the boxplot is 3 . In this boxplot, 4 and 5 are outliers which means very few students disagree with the statement. These students feel that memes do not keep them engaged for a longer period of time. Every student is different and thinks differently. But we see that most of the students are in agreement.

H2: Use of internet memes make classroom teaching learning interesting:

Null hypothesis: Rating of interest in memes as a medium of classroom teaching learning is greater than or equal to three.

Alternative hypothesis: Rating of interest in memes as a medium of classroom teaching learning is less than 3.

As seen in Table 3, null hypothesis is rejected. Hence by doing the hypothesis testing, it is proved that memes make classroom teaching learning interesting. In the box plot drawn (Figure 3), we see that more than $75 \%$ of the data points are in between 1 
and 2 (lower quartile is 1 and median is 2). It means that the data is more towards the agreement side. There is no upper quartile because most of the data points are either 1 or 2 only. The maximum value in the boxplot is 3 . In this boxplot, 4 and 5 are outliers which means very few students disagree with the statement. For them, memes are not an interesting medium for teaching in classrooms. Every student learns in a different way and therefore we can't expect that memes should be interesting for all students. But by hypothesis, we prove that majority of the people think that memes are an interesting medium of teaching learning in classroom.

H3: Internet memes help you understand your course better:

Null hypothesis: The rating of the understanding of course better by the usage of memes is greater than or equal to three.

Alternative hypothesis: The rating of the understanding of course better by the usage of memes is less than 3 .

As seen in Table 3, null hypothesis is rejected. Hence by doing the hypothesis testing, it is concluded that most students agree with the statement that internet memes help them understand their course better. In the box plot drawn, we see that more than $50 \%$ of the data points are between 2 and 3. 25\% of the data points are in between 1 and 2 . And the rest $25 \%$ are in between 3 and 4 . Here only 5th rating is an outlier which means there are very few students who strongly disagree with the statement. There are a few students who disagree with the statement because the experience of teaching learning is different for every student. Some students might understand better with the use of memes, some students may not. But through the hypothesis testing we prove that most of the students agree that memes make them understand their course better.

H4: Extensive use of memes may divert the exact topic which teacher is teaching:

Null hypothesis: The rating of diversion from the exact topic taught by the teacher using extensive memes is greater than or equal to three.

Alternative hypothesis: The rating of diversion from the exact topic taught by the teacher by the use of extensive memes is less than 3 .

As seen in Table 3, null hypothesis is rejected. Hence by doing the hypothesis testing, it is concluded that most of the students agree that extensive use of memes divert the exact topic which the teacher is teaching. In the box plot drawn we see that more than $75 \%$ data points are in between the ratings 1 and 3 (median is 2, lower quartile is 1 and upper quartile is 3). We see that very few percentages of data points are in the ratings 4 or 5 . There are no outliers in this. Therefore, through the hypothesis testing we prove that extensive use of memes may divert the exact topic which teacher is teaching. Memes are only a medium of fun and if teacher incorporates memes as a medium of teaching, it will engage a lot of students into what the teacher is teaching and make them understand better but with an extensive use of memes the environment might become informal and the students might not take the course or the topic seriously.

H5: Teaching of any course with social media (eg. Instagram) is the best combination:

Null hypothesis: The combination of teaching of any course with social media is greater than or equal to three.

Alternative hypothesis: The combination of teaching of any course with social media is less than 3. 
As seen in Table 3, null hypothesis is rejected. Hence by doing the hypothesis testing, it is proved that the teaching of any course with social media is the best combination. In the box plot drawn, we see that more than $50 \%$ of the data points are between 2 and 3. $25 \%$ of the data points are in between 1 and 2 . And the rest $25 \%$ are in between 3 and 4 . Here only 5 th rating is an outlier which means there are very few students who strongly disagree with the statement. There are a few students who disagree with the statement because the experience of teaching learning is different for every student. Some students might understand better with the combination of teaching learning with social media, some students may not. But through the hypothesis testing we prove that most of the students agree that teaching of any course with social media is the best combination.

Overall, by doing the hypothesis testing on all these statements, we see that the median is 2 , which means most of the students agree to the statements. We conclude from the following that memes are an interesting medium of teaching because most students tend to engage more into what the teacher is teaching with the use of memes. However, extensive use of memes may divert the actual topic. Students might not take the course seriously and it may lead to an informal environment between the teacher and students. A little amount of fun should be there but extensive use of anything is harmful. Therefore, we have proven that teaching of any course with social media is the best or ideal combination.

\subsection{Comparative analysis of mid-term results (RQ2)}

RQ2: What is the impact of including meme in classroom practices?

Students' grades of the midterm tests in the last academic year and current year were compared to determine the impact of the memes on the students' performance during MSVR as stated in previous section. Among the two years, one was inclusive of memes in their midterm test paper and the other was the traditional approach where normal questions answers were there. Students' performance was compared in 3 midterm tests with two parameters such as success rate and failure rate in the course as shown in figure 4,5 and 6 . The category of success rate shows an improvement of current year students (students who passed the course with the meme-based approach) with the previous year students (students who passed the course with the traditional approach). 


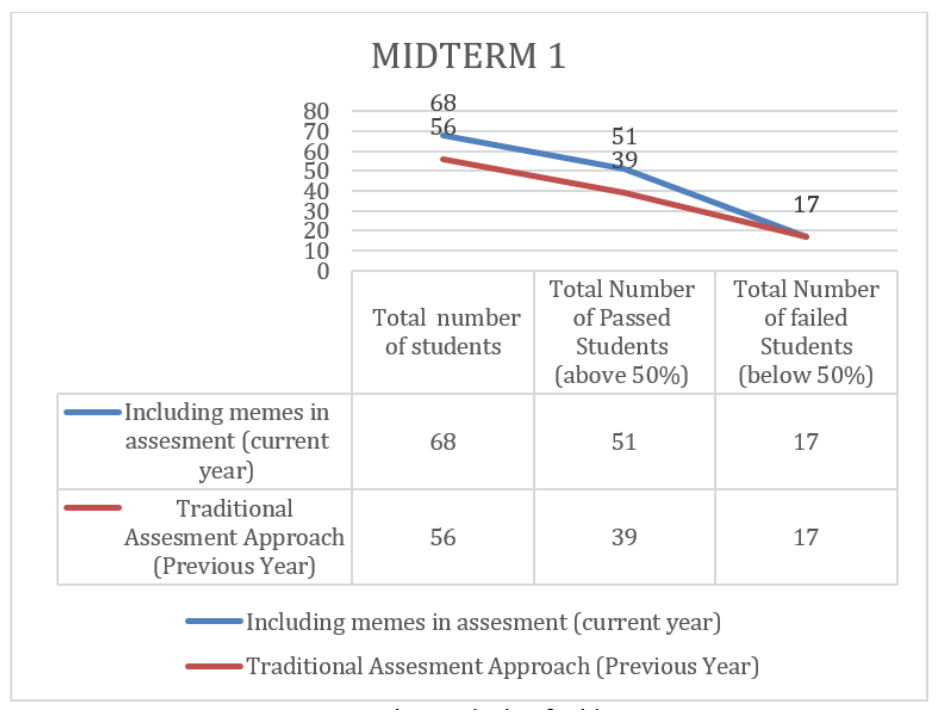

Fig. 6. Comparative analysis of mid-term test 1

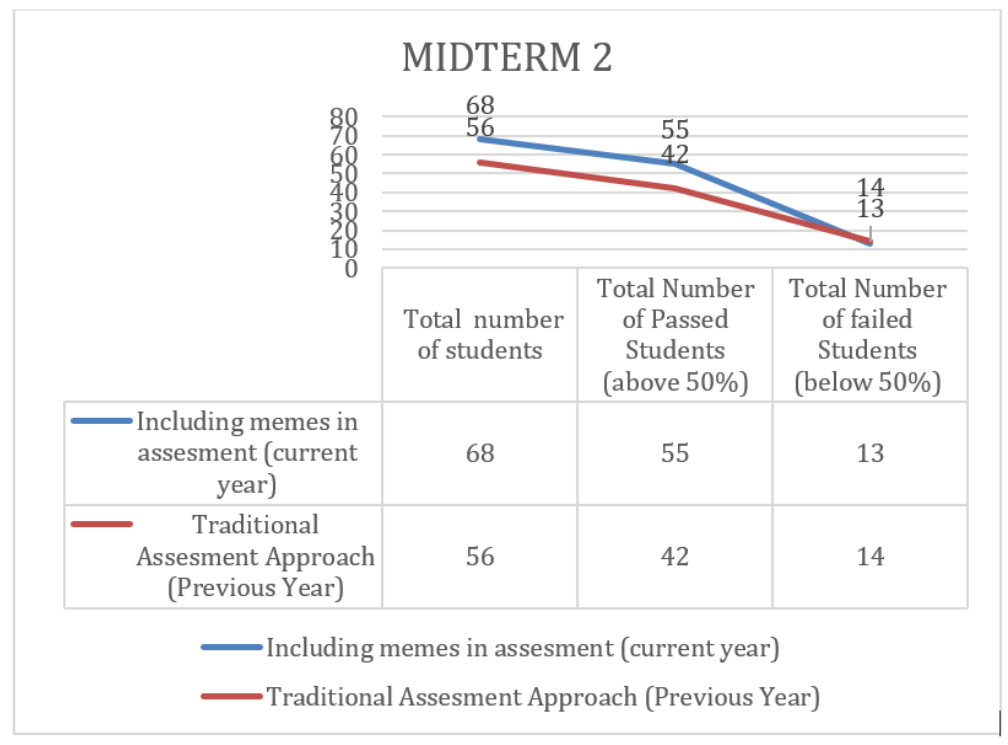

Fig. 7. Comparative analysis of mid-term test 2 


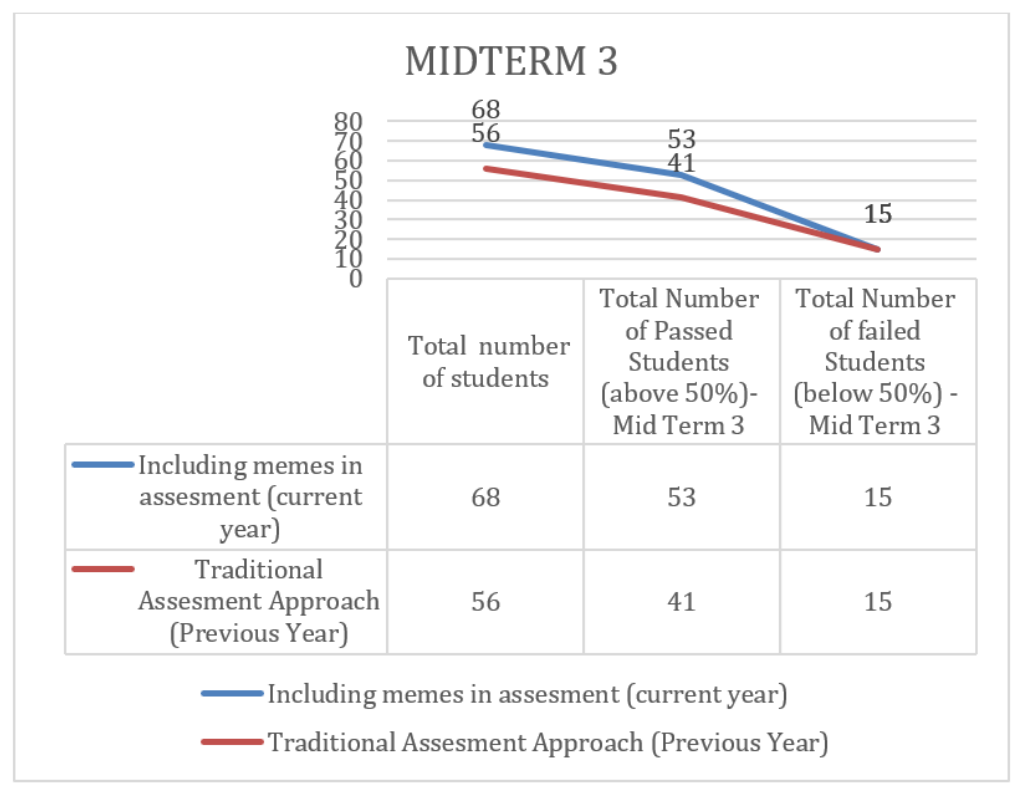

Fig. 8. Comparative analysis of mid-term test 3

Students' grades of the midterm tests in the last academic year and current year were compared to determine the impact of the memes on the students' performance during MSVR as stated in previous section. Among the two years, one was inclusive of memes in their midterm test paper and the other was traditional approach were normal questions answer was there. Students' performance was compared in 3 mid-term tests with two parameters such as success rate and failure rate in the course as shown in figure 4,5 and 6 . The category of success rate shows an improvement of $9.68 \%$ with 56 students who passed the course with the traditional approach as compared to 41 students who passed the course with the meme-based approach. A decrease of $8.45 \%$ was observed in the failure rate category in the semester offered with the meme-based approach as compared to the traditional approach.

\section{Conclusion}

Use of internet memes cannot be considered as an innovative pedagogy, neither can it be used as an alone pedagogic tool. It means that one cannot teach an engineering course using only memes. Engineering is all about solving complex problems whose solution is not through one single methodology. Memes can rather be seen as supplementary tools with some other pedagogic tools like video-based learning, flipped classrooms etc. The authors of this paper neither claimed that Internet memes are the powerful tool in engineering education and its applicability is for all the courses and types of engineering education. The numerical and statistical analysis proves that students like the use of memes in the classroom teaching however it can be changed from 
perception to perception. It doesn't claim that because of memes the subject becomes easy to understand. Soon, more statistical tests like chi square test or correlation test can be conducted on the parameters of acceptability of memes in teaching learning. The future scope of this study is to apply this supplemental technique to any engineering complex course and examines its results for better acceptability worldwide.

\section{$7 \quad$ Acknowledgement}

The authors of the paper would like to thank all the students of School of Technology Management and Engineering, NMIMS University for filling the survey which was circulated for research purpose. We would also like to thank the anonymous reviewers and editors for spending time on our paper by giving constructive reviews.

\section{References}

[1] Website: https://www.statista.com/topics/1145/internet-usage-worldwide/ Last accessed: June, 112020

[2] Website:https://wearesocial.com/blog/2019/01/digital-2019-global-internet-use-accelerates Last accessed: June, 112020

[3] Shabir, G., Hameed, Y. M. Y., Safdar, G., \&Gilani, S. M. F. S. (2014). The impact of social media on youth: A case study of bahawalpur city. Asian Journal of Social Sciences \& Humanities, 3(4), 132-151.

[4] Haddon, L. (2015). Social media and youth. The International Encyclopedia of Digital Communication and Society, 1-9.

[5] Villanueva-Mansilla, E. (2017). Memes, menomes and LOLs: expression and reiteration through digital rhetorical devices. MATRIZes, 11(2), 111-133. https://doi.org/10.11606/ issn.1982-8160.v11i2p111-133

[6] R. Dawkins, The Selfish Gene, Oxford University Press, Oxford, 1976.

[7] Sedliarova, O. M., Solovyeva, N. S., \& Nenasheva, I. A. (2020). Internet Memes as Cultural Education Tools in L2 Teaching. DEStech Transactions on Social Science, Education and Human Science, (icpcs). $\quad$ https://doi.org/10.12783/dtssehs/icpcs2020/ $\underline{33833}$

[8] Sorte, P. B. (2019). Internet memes: classroom perspectives in the context of digital cultures. Educação\&Formação, 4(12 set/dez), 51-66.

[9] Hatfield, S. K. (2018). The Potential Electoral Influence of Internet Memes.

[10] Rotanova, M. B., \&Fedorova, M. V. (2019, April). Internet meme as the Cyber Laughter Culture Phenomenon in Modern Russian Digital Society. In 2019 Communication Strategies in Digital Society Workshop (ComSDS) (pp. 65-69). IEEE. https://doi.org/10.1109/ comsds.2019.8709650

[11] Bini, G., \&Robutti, O. (2019, February). Meanings in Mathematics: using Internet Memes and Augmented Reality to promote mathematical discourse. In Eleventh Congress of the European Society for Research in Mathematics Education (No. 4). Freudenthal Group; Freudenthal Institute; ERME.

[12] Burns, E., Rees, J. C., \& MacLachlan, J. (2016). Everybody phones out: Teaching experiments with Instagram. Spark: UAL Creative Teaching and Learning Journal, 1(2), 79-94. 
[13] Purnama, A. D. (2017). Incorporating memes and instagram to enhance student's participation. LLT Journal: A Journal on Language and Language Teaching, 20(1), 1-14. https:// doi.org/10.24071/11t.2017.200101

[14] Yoon, I. (2016). Why is it not just a joke? Analysis of Internet memes associated with racism and hidden ideology of colorblindness. Journal of Cultural Research in Art Education, 33.

[15] Paul, A. (2019). Memes as means for understanding interpersonal communication: A formative assignment. Communication Teacher, 1-9. https://doi.org/10.1080/17404622.2019. 1681484

[16] Wells, D. D. (2018). You all made dank memes: Using internet memes to promote critical thinking. Journal of Political Science Education, 14(2), 240-248. https://doi.org/10.1080/ 15512169.2017 .1406363

[17] Bini, G. G., \&Robutti, O. (2019, April). Thinking Inside the Post: Investigating the Didactical Use of Mathematical Internet Memes. In PME \& YANDEX (pp. 101-108). International Group for the Psychology of Mathematics Education (PME).

[18] Tureková, I., Lukáčová, D., \& Bánesz, G. (2019). Lighting as an Important Factor of Students' Work Environment. International Journal of Engineering Pedagogy, 9(1), 57-67. https://doi.org/10.3991/ijep.v9i1.9319

[19] Sousa-Vieira, M. E., López-Ardao, J. C., Fernández-Veiga, M., Rodríguez-Pérez, M., \& López-García, C. (2015). Using social learning methodologies in higher education. International Journal of Engineering Pedagogy, 5(2), 64-72. https://doi.org/10.3991/ijep.v5i2. $\underline{4645}$

[20] Laduca, B., Ausdenmoore, A., Katz-Buonincontro, J., Hallinan, K., \& Marshall, K. (2017). An arts-based instructional model for student creativity in engineering design. International Journal of Engineering Pedagogy, 7(1), 34-57. https://doi.org/10.3991/ijep.v7i1.63 $\underline{35}$

[21] Churi, P., Mistry, K., Dhruv, A., \& Wagh, S. (2016, December). Alchemizing Education System by Developing 5 Layered Outcome Based Engineering Education (OBEE) Model. In 2016 IEEE 4th International Conference on MOOCs, Innovation and Technology in Education (MITE) (pp. 338-345). IEEE. https://doi.org/10.1109/mite.2016.073

\section{Authors}

Rishabh Reddy is a student in SVKM's NMIMS Mukesh Patel School of Technology Management and Engineering (MPSTME), where he is pursuing MBA in Technology Management (Minor in Computer Engineering). He is a wholesome person, one capable of prioritizing his work and leisure when needed, and adequately equipped to be a resolute and laser-eyed leader and a willing team-player too. He has a keen interest towards research domain, and he believes that researching helps to gain knowledge immensely. Apart from this He is the Secretary of the Students' Council's Social Impact Committee, while also being the Vice-Chairperson of the college cultural festival, Sattva. Having been an advocate for change and consequence in the modern society, and having always been aware of the dangers and problems faced by it, He has taken part in and led various social initiatives in his college years, namely The Social Conclave, the aforementioned Social Impact Committee, the Serve Out Smiles(SOS) campaign, which aimed at harnessing care and shelter for orphaned pets living in the city, and the annual Blood Donation Drive in college, which saved up to 1300 lives a year. Rishabh3599@gmail.com 
Rishabh Singh is a student in SVKM's NMIMS Mukesh Patel School of Technology Management and Engineering (MPSTME), where he is pursuing MBA in Technology Management (Minor in Computer Engineering). At a young age of 19, he recognized his interest in the field of research and has been working towards it continuously. The domains he's keen about are Data analysis, Security and Education Technology. Rishabh was part of the official technical committee in his college for two years, being head of the Informal's department of the Technical Festival in both years. This has helped him gain experience and skills, both technical and leadership over a period. Along with technical accomplishments he has ensured his contributions towards the betterment of the society by being the head of Hospitality in one of the best social conferences in the world, Social Conclave. He believes in learning beyond boundaries and is always keen in gaining knowledge that is not in his curriculum and part of a different field.

Vidhi Kapoor is undergraduate student pursuing Bachelors of Technology in the field of Data Science from NMIMS' School of Technology Management and Engineering. She is a very hardworking and enthusiastic student, always ready to learn and explore new things. She has interned at various companies to learn and apply her knowledge in industry projects. She has successfully been able to maintain a good balance between academics and extra-curricular. She is a part of various college bodies and has been appointed as the Joint Secretary of the Business and Management Cell of college. She has held positions of Sub Head in Cultural and Social festivals of college. This has helped her in her overall development including team building and leadership qualities. She has a keen interest towards research particularly in the domain of analysis, Machine Learning and Deep Learning and she has been continuously working towards it.

Prof. Prathamesh Churi is Assistant Professor in School of Technology Management and Engineering, NMIMS University. He is also PhD research scholar in Symbiosis International University, India. He is Associate editor of International Journal of Advances in Intelligent Informatics. He is actively involved in peer review process of reputed IEEE and Springer journals. He has been a keynote speaker, chair, convener in the international conferences. He has recently received "Best Young Researcher award" by GISR Foundation for his research contribution in the field of Data Privacy and Security, Education Technology. He is active leader, coach, mentor, volunteer in many ono-profit organizations. He is also involved as board of study member in many universities for curriculum development and educational transformations. He has over 40+ research papers in International Journals and conferences. Prathamesh.churi @gmail.com

Article submitted 2020-04-26. Resubmitted 2020-06-13. Final acceptance 2020-06-14. Final version published as submitted by the authors. 